\title{
Presidenta com a: notas sobre marcações históricas e políticas da língua
}

\author{
Leilane Tolentino Stauffer*
}

\begin{abstract}
Resumo
Neste artigo, buscamos observar as marcas de silenciamento e de evidenciamento em conteúdos divulgados em portais de notícias brasileiros a respeito do uso da expressão presidenta. Por meio dos resultados de busca disponíveis na primeira página do Google, o corpus integra seis matérias veiculadas nos sites Uol, Exame, Veja, iG, Estado de Minas e CartaCapital. A fim de discutirmos as marcações históricas e políticas da língua, ancoramo-nos nas reflexões de Pêcheux (1990), Nunes (2008) e Orlandi (2013, 2012, 2007a,), autores da Análise de Discurso francesa de orientação pecheutiana. Diante do corpus, consideramos necessário também abordar o Jornalismo como meio de disputa, incorporando as contribuições de Biroli e Miguel (2017). A partir de indícios e angulações, observamos como sentidos se constroem no e pelo discurso.

Palavras-chave: Historicidade. Política. Discurso. Silenciamento.

\section{President in the female: notes about historical markings and language policies}

\begin{abstract}
In this article, we intend to observe the silencing and evidence in content published in Brazilian news portals about the use of the term president. Through the search results available on the first page of Google, the corpus integrates six stories published on Uol, Exame, Veja, iG, Estado de Minas and CartaCapital. In order to discuss the historical and political markings of the language, we basead on the reflections of Pêcheux (1990), Nunes (2008) and Orlandi (2007a, 2012, 2013), authors of the French Discourse Analysis of pecheutian orientation. In view of the corpus, we also consider it necessary to approach Journalism as a means of dispute, incorporating the contributions of Biroli and Miguel (2017). From evidences and angulations, we observe how senses are constructed in and by the discourse.
\end{abstract}

Keywords: Historicity. Politics. Discourse. Silencing.

Recebido: $25 / 11 / 2018$

Aceito: $12 / 04 / 2019$

* Centro Federal de Educação Tecnológica de Minas Gerais (CEFET-MG). Mestranda em Estudos de Linguagens. 


\section{Considerações iniciais}

Respirei, e não tive ânimo de olhar para Virgília; senti por cima da página o olhar dela, que me pedia também a mesma cousa, e disse que sim, que iria. Na verdade, um presidente, uma presidenta, um secretário, era resolver as cousas de um modo administrativo.

(Machado de Assis, 2009)

Se considerarmos a linguagem como prática (ORLANDI, 2012), como mediação entre sujeito e realidade social, é possível compreender por que a Análise do Discurso se coloca no lugar da articulação entre o que corresponde à linguística e o que corresponde ao social, histórico e ideológico. A linguagem ocupa o lugar de relação com os modelos de produção social.

Esse entendimento também nos permite afirmar que as palavras não significam em si (ORLANDI, 2012). Só chegamos à significação pelos processos de textualidade e possibilidades de interpretação por meio de um discurso que sustenta e articula palavras. Neste trabalho, partimos da contribuição de Orlandi (2012) a respeito dos processos de produção do discurso que, de acordo com a autora, concentram-se em três momentos:

1. Sua constituição, a partir da memória do dizer, fazendo intervir o contexto históricoideológico mais amplo;

2. Sua formulação, em condições de produção e circunstâncias de enunciação específicas e

3. Sua circulação que se dá em uma certa conjuntura e segundo certas condições. (ORLANDI, 2012, p. 9).

Ao ter em mente tais premissas para análise, observaremos as abordagens e as formações discursivas envolvendo o uso da expressão "presidenta" no português brasileiro, em matérias e artigos de opinião, publicados em portais de notícias do Brasil. Como detalharemos adiante, utilizamos como estratégia para a seleção do corpus o maior mecanismo de busca no ambiente on-line, o Google, posicionado na primeira página com resultados orgânicos.

É necessário pontuar de antemão que a noção de formação discursiva parte da concepção de que o sentido é determinado por formações ideológicas. "As palavras mudam de sentido segundo as posições daqueles que as empregam.” (ORLANDI, 2013, p. 43). O discurso se constrói de sentido por causa das formações discursivas nas quais o sujeito se inscreve. Por isso, Orlandi (2013) afirma que as formações discursivas são responsáveis por conferir sentido às expressões e frases. Na mesma linha, ao afirmar que as formações discursivas representam formações ideológicas, é possível inferir que todos os sentidos são determinados ideologicamente.

Tudo que dizemos tem, pois, um traço ideológico em relação a outros traços ideológicos. E isto não está na essência das palavras mas na discursividade, isto é, na maneira como, no discurso, a ideologia produz seus efeitos, materializando-se nele. O estudo do discurso explicita a maneira como linguagem e ideologia se articulam, se afetam em sua relação recíproca. (ORLANDI, 2013, p. 43).

Para alcançar o objetivo deste trabalho, empreenderemos reflexões sobre a historicidade da língua e sobre os processos de silenciamento no discurso com trabalhos de Pêcheux (1990), Nunes (2008) e Orlandi (2013, 2012, 2007a). Discutiremos também as disputas políticas presentes no discurso jornalístico (BIROLI; MIGUEL, 2017) e observaremos como tais disputas são demarcadas nas matérias que integram nosso corpus. 


\section{A linguagem, a historicidade e a significação: conexões permeáveis}

Ao termos em mente que o propósito do analista do discurso não se direciona exclusivamente à interpretação do texto, mas à compreensão de como se dão os processos de funcionamento e de produção de sentido (ORLANDI, 2012), observamos a existência da noção de incompletude.

A incompletude é característica de todo processo de significação. A relação pensamento/ linguagem/mundo permanece aberta, sendo a interpretação função dessa incompletude, incompletude que consideramos como uma qualidade e não um defeito: a falta, como temos dito em abundância, é também o lugar do possível na linguagem. (ORLANDI, 2012, p. 19).

Assim, na Análise do Discurso, é curioso observar que a opacidade do texto ocupa o lugar central na análise. Joga-se luz ao que está opaco, buscando identificar, como sugere Orlandi (2012), a presença do político, do simbólico, do ideológico, do funcionamento da linguagem e a inserção da língua na história.

A historicidade da língua nos ajuda a ler discursos levando em consideração suas condições de produção, como pondera Nunes (2008, p. 110), “[...] considerando-se a materialidade linguística na qual eles são produzidos e evitando-se tomá-los como documentos transparentes [...]”. Ao olharmos para os discursos pela lente da historicidade, começamos a compreender, como pontua o autor, como eles atestam modos de produzir conhecimento. Por essa razão, consideramos primordial neste trabalho discutirmos também - como faremos à frente - as premissas e as disputas para as concepções das notícias e dos conteúdos jornalísticos.

Nunes (2008) chama atenção para o sentido político da língua, estudado por Orlandi (2007b). $\mathrm{O}$ autor reforça que não há possibilidade de existir uma língua não afetada pelo político. Exemplo disso são as próprias teorias linguísticas, suas formas de organização e todos os instrumentos linguísticos presentes nas instituições, nos espaços de construção e na circulação do conhecimento. Os instrumentos linguísticos fundam uma unidade para a língua, e "a produção dessa unidade não é jamais neutra, ela é condicionada pelo funcionamento da representação linguística, que é também uma representação política" (NUNES, 2008, p. 120). O autor sugere que compreender as formas de saber linguístico na história auxilia no processo de posicionamento crítico. Nunes (2008) entende que esse tipo de posicionamento se situa em pelo menos três instâncias:

a) um posicionamento diante das ciências da linguagem, que procura mostrar o modo como o político e o histórico estão ou não presentes nas teorias e de que modo; b) um posicionamento diante da produção dos instrumentos linguísticos, com a análise e a crítica das obras recentemente publicadas, considerando-se a memória do saber linguístico; [...] c) um posicionamento junto à "opinião pública", com a produção de materiais de divulgação e a realização de fóruns de discussão sobre os conhecimentos linguísticos. (NUNES, 2008, p. 120).

Orlandi (2012) defende que, para a análise do discurso, não são primordiais os atos realizados em primeira instância e sim o fato de que a realidade, por meio da produção imaginária e da produção discursiva, se constitui em sentidos propostos pelo sujeito. "O sujeito, por sua vez, ao dizer, se significa e significa o próprio mundo. Nessa perspectiva é que consideramos que a linguagem é uma prática." (ORLANDI, 2012, p. 44). A prática que a autora aborda está ligada à prática de sentidos, sentidos simbólicos que intervêm no real, que significam o mundo. "O sentido é história e o sujeito se faz (se significa) na historicidade em que está inscrito.” (ORLANDI, 2012, p. 44).

Aspecto interessante levantado por Nunes (2008) também vinculado à historicidade diz respeito à periodização, ponto comum às práticas jornalísticas ao pautar conteúdos. $\mathrm{O}$ autor assinala que 
se a periodização cronológica se faz necessária para localizar em HIL [História das Ideias Linguísticas] certos fatos e comparar uma tradição linguística com outra, a perspectiva discursiva não estaciona em seus efeitos. Ela considera também o modo como a temporalidade é construída em cada discurso, como ela funciona por fixação imaginária, por retomadas, por re-atualizações da memória. (NUNES, 2008, p. 100-111).

Em nosso corpus, notamos que os materiais veiculados em portais de notícias que apareceram na primeira página de resultados para a busca "uso da palavra presidenta" no Google fazem inferência à marcação de gênero pontuada pela presidenta eleita Dilma Rousseff. Isso nos permite afirmar que a inscrição histórica da primeira vez que uma mulher ocupou a presidência do Brasil e o evidenciamento da expressão no feminino por Dilma Rousseff foram determinantes para pautar a discussão do uso da expressão.

Ao considerarmos ainda a contribuição de Nunes (2008), quando o autor sinaliza as re-atualizações da memória, observamos essa construção mais claramente indicada em matéria do jornal Estado de Minas, a penúltima listada nos resultados do Google. Vamos nos ater, por enquanto, ao título e ao bigode da matéria destacados nos resultados da busca. Veiculada em 31 de maio de 2016, o título da matéria enfatiza que "Governo Temer veta palavra 'presidenta' em publicações da EBC" (PRATES, 2016, on-line). O bigode, que no Jornalismo cumpre a função de complementar o significado do título, traz a seguinte informação: "Novo comando da Empresa Brasileira de Comunicação proibiu uso da palavra no feminino, como exigia Dilma Rousseff" (PRATES, 2016, on-line).

Por esses destaques, é possível perceber a ênfase à reatualização da memória, reforçando o contexto político brasileiro de conflitos, em que Michel Temer e Dilma Rousseff, que antes eram aliados, são posicionados, na marcação temporal desta notícia, como rivais. É curioso perceber também o destaque ao processo de silenciamento com a atitude de proibir o uso da palavra no feminino em um canal público de comunicação, a Empresa Brasil de Comunicação (EBC).

Pêchuex (1990), ao olhar para o que as questões históricas das revoluções podem nos dizer, acredita que esses momentos tocam, por diversas vias, em dualidades antes localizadas em ambientes distintos, como o visível e o invisível, o existente e o alhures, o presente e as diferentes mobilidades da ausência. Diante desses pares antitéticos que se atravessam e coexistem em diversas situações, o autor faz um questionamento importante para a nossa problematização: "não seria o caso de designar ao mesmo tempo esta questão, onde o real vem se afrontar com o imaginário, diz respeito também à linguagem, na medida em que ela especifica a existência do simbólico para o animal humano?" (PÊCHEUX, 1990, p. 8).

Pensamos que o problema central do nosso corpus se instaura no confronto entre o real e o imaginário. A linguagem, ao mesmo tempo, descortina e dá abrigo à problemática da representatividade feminina na democracia brasileira. Ao ter como base a flexão de gênero em um substantivo para marcar o acontecimento histórico da presença de uma mulher no mais alto cargo do poder executivo do Brasil, observamos a língua sendo explorada para reafirmar a expressão presidenta, em um processo de evidenciamento que relaciona história e linguagem. Essa mesma língua, mobilizada por outras formações discursivas, deixa escapar os indícios que silenciam o discurso de afirmação de gênero.

\section{As raízes do silenciamento no discurso}

Partir do princípio da marcação simbólica da língua implica nos fazer pensar nos processos de evidenciamento e silenciamento do discurso a partir do léxico, da escolha desta e não daquela expressão, e nos processos de julgamento - mobilizados pelo Estado, pela imprensa, por diversos órgãos reguladores e pela própria sociedade - que avaliam se determinada expressão é adequada ou 
não para designar algum contexto, como é o caso do nosso corpus. Pêcheux (1990) chama atenção para o fato de que a existência do invisível e da ausência está inscrita estruturalmente nas formas linguísticas. Entre tais formas linguísticas, estão a

[...] da negação, do hipotético, das diferentes modalidades que expressão um "desejo", etc., no jogo variável das formas que permutam o presente com o passado e o futuro, a constatação assertica com o imperativo da ordem e a falta de asserção do infinitivo, a coincidência enunciativa do pronome eu com o irrealizado nós e a alteridade do ele (ela) e do eles (elas)... através das estruturas que lhe são próprias, toda língua está necessariamente em relação com o "não está", o "não está mais", o "ainda não está" e o "nunca estará" da percepção imediata: nela se inscreve assim a eficácia omni-histórica da ideologia como tendência incontornável a representar as origens e os fins últimos, o alhures, o além o invisível. (PÊCHEUX, 1990, p. 8, destaques do autor).

Atrelado a essa noção, Orlandi (2007, p. 12), na obra As formas do silêncio, acredita que o estudo do silenciamento - que pode ser entendido não como silêncio exatamente, mas como o processo de pôr em silêncio - aponta para a existência de sentidos silenciados "[...] que nos faz entender uma dimensão do não-dito absolutamente distinta da que se tem estudado sob a rubrica do "implícito"”. É interessante ressaltar a perspectiva da autora, ao afirmar que existe uma dimensão do silêncio vinculada à noção de incompletude da linguagem. Para Orlandi (2007, p. 12), "todo dizer é uma relação fundamental com o não-dizer".

O caráter fundador do silêncio é mencionado por Orlandi (2007). Por ele, concentra-se a ideia de que o sentido pode ser outro além do preestabelecido e que o mais importante nunca se diz. Acreditamos que a característica fundante repercute no processo de silenciamento. A autora afirma que o silêncio não é complemento de linguagem. Ao contrário, o silêncio significa "[...] garantia do movimento de sentidos. Sempre se diz a partir do silêncio" (ORLANDI, 2007, p. 23).

A autora estrutura o silêncio por meio de duas distinções: a do silêncio fundador, encontrado nas palavras e responsável por significar o não-dito, e a política do silêncio que é subdivida em duas formas, que são: "1) silêncio constitutivo, o que nos indica que para dizer é preciso não-dizer (uma palavra apaga necessariamente as "outras" palavras); 2) o silêncio local, que se refere à censura propriamente (àquilo que é proibido dizer em uma certa conjuntura).” (ORLANDI, 2007, p. 24).

Nos processos de construção de sentido em textos jornalísticos, podemos afirmar que há a política do silêncio com a estrutura tanto do silêncio constitutivo quanto do silêncio local. Em nosso corpus, especificamente, como veremos adiante, notamos a presença do silêncio constitutivo.

\section{O Jornalismo como meio de disputa}

Antes de conduzirmos as análises, consideramos necessário pontuar os entremeios da linguagem e dos processos de produção jornalística. Na obra Análise de Discurso, Orlandi (2013, p. 30) observa que as circunstâncias que mostram os sentidos não se concentram apenas nas palavras, nos textos. Os sentidos estão estritamente vinculados ao meio, "nas condições em que eles são produzidos e que não dependem só das intenções dos sujeitos".

Nesse sentido, a produção de Biroli e Miguel (2017) discute o impacto social que os meios de comunicação de massa exercem, especialmente diante das formas de conflito político no Brasil contemporâneo. Compreendemos, aqui, o impacto social como sinônimo de política. A respeito da esfera política do discurso, Orlandi (2012, p. 34) a entende enquanto relações de força que se simbolizam, “[...] o político reside no fato de que os sentidos têm direções determinadas pela forma da organização social que se impõem a um indivíduo ideologicamente interpelado.”. 
Diante desse diálogo, Biroli e Miguel (2017) chamam atenção para a importância de adentrar profundamente na compreensão dos processos produtivos da mídia e suas relações com as estratégias dos agentes políticos. A mídia sobre a qual os autores concentram-se diz respeito ao jornalismo hegemônico, “[...] entendido como o sistema que reúne, seleciona, hierarquiza, organiza e vende informações sobre a atualidade [...]” (BIROLI; MIGUEL, 2017, p. 8) e possui impacto político.

Os autores problematizam duas situações de peso exercidas pela mídia nos processos políticos. A primeira se relaciona com a influência sobre os agentes políticos, que moldam seus discursos às formas convenientes à cobertura dos meios. A segunda está ligada ao impacto sobre o público, levando em consideração as representações construídas pela mídia. Sobre essa última situação, que associa representações e impacto sobre o público, é que acreditamos que nosso corpus nos dá passagem para análise. O posicionamento de gênero na expressão "presidenta" pode ser considerado, antes de mais nada, marca de uma representação.

A respeito do impacto sobre o público, é possível estabelecer diálogo com as considerações de Orlandi (2012). Para a autora, pensar o texto sob a ótica da interpretação confirma que a relação entre discurso e texto não é dada. Pelo contrário, está sendo constantemente elaborada. E essa elaboração pode ser observada "[...] na maneira como, nos vestígios da textualização, o sujeito se 'ancora', se 'engata', em um e não outro discurso, em um e não outro sentido.” (ORLANDI, 2012, p. 66). A autora justifica e endossa sua defesa de que o texto é heterogêneo, afetado de várias formas pela discursividade.

O texto mostra como se organiza a discursividade, isto é, como o sujeito está posto, como ele está significando sua posição, como a partir de suas condições (circunstâncias da enunciação e memória) ele está praticando a relação do mundo com o simbólico, materializando sentidos, textualizando, formulando, breve, "falando". (ORLANDI, 2012, p. 67).

Podemos afirmar que estão presentes no texto jornalístico os vestígios da textualização. Neles, as ancoragens linguísticas do enunciador nos remetem também para a linha editorial do veículo, revelando apoios e fundamentações políticas. Em função desses pontos, Biroli e Miguel (2017) contestam os valores da imparcialidade e da objetividade defendidos pelo Jornalismo. Se, por um lado, eles servem como resistência a pressões de governos e agentes econômicos, por outro mascaram a adesão a visões de alguns grupos.

Numa sociedade cindida por clivagens (de classe, de gênero, de raça, entre muitas outras), a apresentação de visões parciais como se fossem "nenhuma posição" permite que as experiências e os interesses de alguns grupos sejam universalizados. Como as clivagens que diferenciam os grupos correspondem a privilégios, estamos falando de hierarquias socialmente estruturadas que ganham forma no debate público por meio da visibilização e da vocalização desigual dos grupos (BIROLI; MIGUEL, 2017, p. 11-12).

Tais constatações podem ser aplicadas diretamente em nosso corpus. Por meio do levantamento da discussão sobre o uso do termo presidenta, observaremos os indícios de posicionamento, o silenciamento e o evidenciamento presentes nas matérias. Descreveremos, abaixo, o processo de seleção do corpus e sua constituição.

\section{O corpus}

Neste artigo, buscamos observar as formas de silenciamento e evidenciamento presentes em matérias e textos opinativos em sites de notícias a respeito do uso da expressão presidenta. Para 
isso, estabelecemos algumas estratégias para a seleção do corpus. É preciso sinalizar, primeiramente, que os conteúdos divulgados nos meios de comunicação de massa a respeito do assunto surgiram da adoção da expressão, feita por Dilma Rousseff, primeira mulher eleita para governar o Brasil, oficializando-a em documentos públicos, em todas as instâncias de governo e reforçando que era assim que desejava ser chamada.

Diante da marcação distinta, foi possível perceber inúmeras discussões mobilizadas pelos meios de comunicação de massa a respeito da legitimidade do uso da expressão - questionamento que, como veremos nas análises, já pode suscitar a discussão a respeito do silenciamento. Dentre os filtros estabelecidos para a constituição do nosso corpus, optamos por filtrar os conteúdos veiculados em portais de notícias. Chegamos a seis matérias que formam o corpus por meio de outro critério: os resultados orgânicos que apareceram na primeira página do Google, em busca realizada em 19 de junho de 2018, às 16h35. Tomamos por base a ferramenta de pesquisa, ao observarmos o movimento das buscas na Internet. Além de o Google ser o maior buscador do mundo, as ferramentas de buscas, de forma geral, desempenham função forte e relevante para as visitas em sites. É por meio dos resultados, orgânicos e patrocinados, que grande parte de usuários chega às páginas. Além disso, os resultados da primeira página indicam aspectos como boa acessibilidade da página, layout responsivo, relevância de conteúdo e uso adequado de palavras-chave.

Ao lançarmos a frase "uso da palavra presidenta" no buscador, não encontramos links patrocinados. Deparamo-nos, na primeira página, com sites relacionados a dicionários e discussão de assuntos gramaticais e seis conteúdos correspondentes a portais de notícias. São eles: Uol, Exame, Veja, iG, Estado de Minas e CartaCapital, listados nesta ordem. No quadro, abaixo, relacionamos os portais, os títulos das matérias, editorias nas quais foram pautadas, autores e datas de veiculação - quando informadas.

Quadro 1 - Formação do Corpus

\begin{tabular}{|l|l|l|l|l|}
\hline \multicolumn{1}{|c|}{ Portal } & \multicolumn{1}{|c|}{ Título } & \multicolumn{1}{c|}{ Editoria } & \multicolumn{1}{c|}{ Autoria } & Data de veiculação \\
\hline Uol & $\begin{array}{l}\text { A presidente ou a } \\
\text { presidenta? Qual } \\
\text { das formas devemos } \\
\text { utilizar? }\end{array}$ & $\begin{array}{l}\text { Gramática } \mid \\
\text { Ortografia }\end{array}$ & $\begin{array}{l}\text { Vânia Maria do } \\
\text { Nascimento Duarte }\end{array}$ & Não informada \\
\hline Exame & $\begin{array}{l}\text { O termo "presidenta" } \\
\text { está mesmo errado } \\
\text { gramaticamente? }\end{array}$ & $\begin{array}{l}\text { Carreira - Você } \\
\text { S/A }\end{array}$ & Camila Pati & $11 / 08 / 2016$ \\
\hline Veja & $\begin{array}{l}\text { Palavra do Ano: } \\
\text { Presidente/presidenta }\end{array}$ & $\begin{array}{l}\text { Blog Sobre } \\
\text { Palavras }\end{array}$ & Sérgio Rodrigues & $21 / 10 / 2010$ \\
\hline Estado de Minas & $\begin{array}{l}\text { "Presidenta" existe } \\
\text { na língua portuguesa } \\
\text { desde 1872 }\end{array}$ & Educação & Não informada & $15 / 09 / 2011$ \\
\hline CartaCapital & $\begin{array}{l}\text { Governo Temer veta } \\
\text { palavra 'presidenta" } \\
\text { em publicações da } \\
\text { EBC }\end{array}$ & $\begin{array}{l}\text { Política } \\
\text { étar "presidenta" } \\
\text { "presidente" }\end{array}$ & Maria Clara Prates & $31 / 05 / 2016$ \\
\hline
\end{tabular}

Fonte: Elaborado pela autora deste artigo.

Com auxílio das reflexões teóricas empreendidas até aqui, propomos observar as angulações e estratégias discursivas mobilizadas nesses conteúdos diante da representação de gênero, marcada na língua, que reflete o fato histórico de uma mulher ocupar, pela primeira vez, a presidência da República Federativa do Brasil. 


\section{Análise}

Antes de proceder às análises, compreendemos que a designação da expressão presidenta e as tentativas de evidenciamento e silenciamento dos sentidos da expressão em textos jornalísticos são exemplos da afirmação de Orlandi (2013). Como defende a autora, estamos sujeitos à linguagem e, assim estando, é preciso saber que não existe neutralidade sequer nos usos mais simples e corriqueiros dos signos. "A entrada no simbólico é irremediável e permanente: estamos comprometidos com os sentidos e o político.” (ORLANDI, 2013, p. 9). Assim, consideraremos as estratégias discursivas para observar os percursos de silenciamento e evidenciamento.

\section{Títulos e bigodes}

A primeira estratégia diz respeito aos títulos e aos bigodes, destaques posicionados abaixo dos títulos, nas matérias. Olhar para esses elementos textuais faz-se importante se considerarmos que eles são os primeiros indícios do discurso e já revelam as angulações presentes no conteúdo. No quadro abaixo, apresentamos os títulos e os destaques de cada matéria.

\section{Quadro 2 - Relação de títulos, chapéus e bigodes}

\begin{tabular}{|l|l|l|}
\hline \multicolumn{1}{|c|}{ Portal } & \multicolumn{1}{|c|}{ Título } & \multicolumn{1}{c|}{ Bigode } \\
\hline Uol & $\begin{array}{l}\text { A presidente ou a presidenta? Qual } \\
\text { das formas devemos utilizar? }\end{array}$ & - \\
\hline Vejame & $\begin{array}{l}\text { O termo "presidenta" está mesmo } \\
\text { errado gramaticamente? }\end{array}$ & $\begin{array}{l}\text { Ministra Cármen Lúcia não quer ser chamada de } \\
\text { presidenta porque "é uma uma (sic) amante da língua } \\
\text { portuguesa". Ela tem razão? }\end{array}$ \\
\hline iG & $\begin{array}{l}\text { Palavra do Ano: Presidente/ } \\
\text { presidenta }\end{array}$ & $\begin{array}{l}\text { Publicado em 21 de outubro de 2010. Reitero, no dia } \\
\text { da posse da presidente Dilma Rousseff, a preferência } \\
\text { pessoal que manifestei então. }\end{array}$ \\
\hline Estado de Minas & $\begin{array}{l}\text { Governo Temer veta palavra } \\
\text { "Presidenta' em publicações da EBC } \\
\text { portuguesa desde 1872 }\end{array}$ & $\begin{array}{l}\text { Palavra foi incorporada aos dicionários em 1925, } \\
\text { segundo estudo da equipe do Dicionário Aurélio, feito } \\
\text { com exclusividade para o iG }\end{array}$ \\
\hline CartaCapital & $\begin{array}{l}\text { Fovo comando da Empresa Brasileira de Comunicação } \\
\text { Rousseff }\end{array}$ \\
\hline
\end{tabular}

Fonte: Elaborado pela autora deste artigo.

O título do site Uol parte do evidenciamento da dúvida, questionando qual das duas formas presidente ou presidenta - deve ser utilizada. É possível afirmar que o título busca aproximar-se do público leitor por meio da conjugação do verbo "dever" na primeira pessoa do plural. Com a pergunta “qual das formas devemos utilizar?" (DUARTE, 2018, on-line), portal, autora e leitores colocam-se em pé de igualdade como se partilhassem a mesma dúvida. Ao longo de toda a matéria e seguindo a ideia do título, foi evidenciada a questão linguística. As formações discursivas que constroem o lead, primeiro parágrafo do texto, reforçam esse argumento:

Um fato inédito demarcou o resultado obtido por meio das últimas eleições no Brasil - o de uma mulher eleger-se como alguém que comandará a nação durante um determinado 
tempo. Tal ocorrência desencadeou, entre outros fatores, alguns aspectos relacionados à própria linguagem, tornando-se alvo de questionamentos por parte de algumas pessoas. (DUARTE, 2018, on-line).

Pelo parágrafo, observamos que a matéria vincula as discussões a respeito do termo a problematizações estritamente linguísticas.

Da mesma forma que o título do Uol, a matéria veiculada no site da revista Exame tem, como ponto de partida, uma pergunta. O título da matéria já parte do pressuposto de que o termo presidenta corresponde a um erro gramatical. O bigode parece complementar o sentido na tentativa de justificar o questionamento. Trata-se da afirmação da ministra Cármen Lúcia, presidente do Supremo Tribunal Federal (STF). Apesar de o foco da matéria ser o cargo da ministra do STF, é possível perceber que a discussão a respeito da escolha de Dilma Rousseff em ser chamada de presidenta é, implicitamente, retomada. O bigode da matéria ressalta a afirmação de Cármen Lúcia, cujo sentido apela para o valor do português falado corretamente. É o apelo a esse valor que supõe que a expressão presidenta, no feminino, esteja errada.

O assunto foi pautado na Veja, por sua vez, em um blog. Escrito por Sérgio Rodrigues, o blog "Sobre Palavras" se apresenta com a seguinte formação discursiva: "Este blog tira dúvidas dos leitores sobre o português falado no Brasil. Atualizado de segunda a sexta, foge do ranço professoral e persegue o equilíbrio entre o tradicional e o novo." (VEJA, 2010, on-line). O bigode do texto evidencia o caráter opinativo predominante no texto.

Ao contrário dos três primeiros conteúdos abordados até aqui, as matérias dos sites iG e CartaCapital, pelos títulos e bigodes, parecem buscar defender a marcação política da expressão presidenta. Em vez de mobilizar questionamentos, os títulos e os bigodes trazem afirmações e evidenciam informações históricas a respeito da existência da expressão nos dicionários brasileiros e na literatura brasileira, respectivamente. $\mathrm{O}$ iG, inclusive, destacou, em forma de infográfico, estudo exclusivo elaborado pela equipe do dicionário Aurélio.

O enlaçamento do título da matéria do Estado de Minas, publicada em 31/05/2016, reforça a marcação política por outra situação. Somente as matérias do Estado de Minas e da revista Exame foram publicadas depois de Dilma Rousseff ter sido afastada e deposta do cargo ao qual foi eleita. $\mathrm{O}$ título da matéria do Estado de Minas evidencia e repercute a proibição do uso do termo no feminino pelo governo de Michel Temer, antes aliado e vice-presidente de Dilma Rousseffe, após a condução do processo de impeachment, encarado como rival. O título e o bigode reforçam, por meio da proibição, o impacto de resistência diante da expressão presidenta.

\section{O processo de (des)legitimação com as perguntas}

Observamos a presença de perguntas como estratégia discursiva em várias matérias. Além dos títulos e bigodes, os veículos mobilizaram questionamentos ao longo dos textos produzindo efeitos de legitimação e de deslegitimação. Na CartaCapital, por exemplo, veículo de posicionamento político declaradamente de esquerda no Brasil, observamos que o repórter Diego Antonio Rodriguez estruturou toda a matéria em seis perguntas.

1) Afinal, a palavra "presidenta" existe?

2) Mas isso foi inventado agora, não?

3) Eu nunca tinha ouvido ninguém usar "presidenta". Por que a Dilma e o PT teimam nessa palavra?

4) Então o uso de "presidenta" é político?

5) No caso de palavras como "agente" e "pedinte", a forma feminina não existe. Por que 
com "presidenta" é diferente?

6) Acho feio e não vou usar. Estou errado? (RODRIGUEZ, 2014, on-line).

É possível notar que a estrutura das perguntas corresponde a possíveis questionamentos dos cidadãos e todas as respostas buscam desconstruir o pensamento dominante de que o termo esteja errado gramaticalmente. A matéria evidencia, inclusive na legenda da fotografia de Dilma Rousseff, que o uso da expressão no feminino simboliza a marca histórica de uma mulher estar à frente, pela primeira vez, do poder executivo do Brasil. A legenda da imagem enfatiza: "Dilma Rousseff: uso do termo deixa claro que é a primeira vez que temos uma mandatária do sexo feminino" (RODRIGUEZ, 2014, on-line). Pela última pergunta mobilizada por Rodriguez (2014), é possível constatar que o texto da CartaCapital foi o único que pontuou o ato de respeito em chamar uma pessoa como ela se autodenomina.

6) Acho feio e não vou usar. Estou errado?

Não está, você tem a liberdade de falar "presidente" para referir-se a Dilma ou outra chefe máxima do executivo sem cometer erro algum. Mas é sempre bom respeitar a forma como uma pessoa se autodenomina, é um sinal de respeito. O governador de São Paulo, Geraldo Alckmin (PSDB), por exemplo, pensa desta forma. Chamou Dilma Rousseff de "presidenta" numa entrevista à Globonews. "Devemos chamar as pessoas pelo que elas gostam de ser chamadas", concluiu. (RODRIGUEZ, 2014, on-line).

Um dos destaques do texto divulgado no Uol, por sua vez, apresenta o questionamento com efeito diferente dos questionamentos propostos no conteúdo divulgado em CartaCapital. A pergunta “Afinal, Dilma Rousseff ocupará o cargo de presidente ou presidenta do Brasil?", presente no texto assinado por Duarte, no Uol, parece invalidar o uso da expressão. A pergunta, em segundo momento, cumpre a função de gancho para pontuar os aspectos gramaticais da flexão de gênero ao substantivo.

\section{Evidenciamentos que silenciam}

Ainda a respeito da matéria do Uol, o desenvolvimento do conteúdo recorre às afirmações de linguistas brasileiros renomados - como Celso Cunha, Evanildo Bechara, Luís Antônio Sacconi, João Ribeiro e Domingos Paschoal Cegalla - para tratar e legitimar a questão. É curioso observar o evidenciamento dado pela autora para a expressão "a presidente", invertendo a ordem da discussão levantada pela situação. "Divergências deixadas à parte, o fato é que forma 'a presidente', (sic) está correta, justamente pelo fato de integrar ao caso relacionado aos substantivos denominados comuns de dois. Portanto, podemos perfeitamente dizer: a presidente.” (DUARTE, 2018, on-line). O encerramento da matéria, por sua vez, ao evidenciar o que a enunciadora supõe ser de interesse dos leitores, silencia outras possíveis leituras e não abre margem para a discussão a respeito de como Dilma Rousseff gostaria de ser chamada. "Desta forma, o que mais nos interessa é saber qual das formas estão corretas, não é verdade? Pois bem, as duas estão de acordo com o padrão formal da linguagem. Logo, empregar esta ou aquela é opção de cada usuário." (DUARTE, 2018, on-line). Ao contrário do que observamos em CartaCapital, o que está posto, em primeira instância, no Uol, é como as pessoas gostariam de pronunciar a expressão.

Destacamos, aqui, dois trechos do texto publicado no site da Exame. No primeiro deles, Pati (2016), após evidenciar que a ministra Cármen Lúcia prefere ser chamada de presidente, e não presidenta, cogita, inicialmente, como hipótese que a expressão, flexionada no feminino, esteja errada, para, então, explicar a existência da expressão nos dicionários brasileiros. 
Com isso surge novamente a dúvida polêmica: presidenta está mesmo errado gramaticalmente? 'Presidenta, segundo o 'Aurélio', é 'mulher que preside', distinta de presidente, que é 'pessoa que preside' ou 'o presidente da República", diz o professor Reinaldo Passadori, presidente e CEO do Instituto Passadori. Ou seja, o termo presidenta pode causar estranheza, mas não está incorreto. (PATI, 2016, on-line).

É interessante notar a mobilização do "não" e do adjetivo "incorreto", ambos com conotação negativa, na frase "não está incorreto", para afirmar que a expressão está correta. Como lembra Orlandi (2012), um discurso não é construído por um único texto ou por textos existentes. É importante ressaltar que o discurso se mobiliza e se constrói por uma quantidade aberta de textos, sejam eles já existentes e circulantes na sociedade ou mesmo textos que ainda virão a existir.

O segundo trecho da matéria, localizado já no encerramento, acolhe a explicação do professor Reinaldo Passadori, presidente e CEO do Instituto Passadori, que reforça a apropriação do termo para valorizar a presença da figura feminina na política. Apesar do registro, Pati (2016) finaliza o texto com a seguinte formação discursiva: "Sendo assim, é possível optar tanto por presidente como por presidenta sem fazer desfeita para língua portuguesa." (PATI, 2016, on-line). Observamos, assim, que a pauta prioritária do texto, em termos de abordagem, concentra-se, exclusivamente, em correções e validações gramaticais, desconsiderando a própria marcação política da língua.

No blog "Sobre Palavras", na Veja, apesar de Rodrigues (2010) contemplar a abordagem política da expressão no feminino, com a formação discursiva "a lógica desse tipo de embate na língua costuma ser muito mais política do que técnica” (RODRIGUES, 2010, on-line), a preferência e o desfecho do texto silenciam o peso político da escolha e reduzem o debate acerca do uso com base numa questão de opinião.

No fim das contas, cabe ao falante julgar os méritos de cada palavra e fazer sua escolha - exatamente como na política. Ou fazer sua escolha de forma inconsciente, de orelhada - o que também ocorre com frequência, infelizmente, na política. E para não dizerem que fiquei em cima do muro: no meu dicionário pessoal, presidente é uma palavra de dois gêneros. Acho que tem sonoridade melhor, além de evitar um possível surto politicamente correto que acabe por povoar o mundo de (argh!) gerentas, atendentas e adolescentas. Se o Brasil terá ano que vem um presidente ou uma presidente, só pretendo mudar o artigo. (RODRIGUES, 2010, on-line).

\section{Considerações finais}

Partimos da reflexão do linguista Émile Benveniste, em Problemas da Linguística Geral I, ao afirmar que "o homem sentiu sempre - e os poetas frequentemente cantaram - o poder fundador da linguagem, que instaura uma realidade imaginária, anima as coisas inertes, faz ver o que ainda não existe, traz de volta o que desapareceu" (BENVENISTE, 1995, p. 27). A potência da linguagem se revela nas marcas da história, construídas no e pelo discurso. E, como pontua Orlandi (2012, p. 9), “é na formulação que a linguagem ganha vida, que a memória se atualiza, que os sentidos se decidem, que o sujeito se mostra (e se esconde)".

Pela análise do corpus, refletimos sobre a palavra e sua relação com o discurso. No interior da língua, como Pêcheux (1999, p. 11) observa, é possível estabelecer "a maneira política de negar a política". Acreditamos que o evidenciamento do substantivo presidenta, flexionado no feminino, seja a marcação política de Dilma Rousseff em negar a política cristalizada no Brasil pelo imaginário e pelos índices que comprovam a maior parte dos cargos políticos ser ocupada por homens. 
A respeito da apropriação feita pela imprensa, verificável em matérias presentes em nosso corpus, podemos observar como questionamentos sobre o uso "adequado" da língua - posicionada como valor maior - buscaram deslegitimar e silenciar a afirmação política da expressão presidenta, que evidencia a primeira vez que uma mulher foi eleita para comandar a nação brasileira. Percebemos também a estratégia de silenciar a expressão, e consequentemente a discussão política, por meio da crítica mobilizada a respeito do uso correto ou não do termo. Ancoramo-nos, por fim, na contribuição de Orlandi (2013) que entende que buscar compreender como os discursos funcionam significa também se localizar no que a autora chama de duplo jogo da memória: a memória institucional, que pretende estabilizar e cristalizar discursos, e a memória fruto do esquecimento, que dá espaço ao diferente, à ruptura, à presença do outro.

[...] se, de um lado, há imprevisibilidade na relação do sujeito com o sentido, da linguagem com o mundo, toda formação social, no entanto, tem formas de controle da interpretação, que são historicamente determinadas: há modos de se interpretar, não é todo mundo que pode interpretar de acordo com sua vontade, há especialistas, há um corpo social a quem se delegam poderes de interpretar (logo de "atribuir" sentidos), tais como o juiz, o professor, o advogado, o padre, etc. Os sentidos estão sempre "administrados", não estão soltos. (ORLANDI, 2013, p. 10).

Compreendemos, assim, a existência da administração dos sentidos da expressão presidenta proposta e conduzida pela imprensa brasileira. 


\section{Referências}

ASSIS, Machado. Memórias póstumas de Brás Cubas. Edição eletrônica, 2009. Disponível em: http://www.machadodeassis.net/hiperTx_romances/obras/brascubas.htm. Acesso em: 29 jun. 2018.

BENVENISTE, Émile. Problemas de Linguística Geral I. Campinas: Pontes, 1995.

BIROLI, Flávia; MIGUEL, Luis Felipe. Notícias em disputa: mídia, democracia e formação de preferências no Brasil. São Paulo: Contexto, 2017.

DUARTE, Vânia Maria do Nascimento. A presidente ou a presidenta? Qual das formas devemos utilizar? Uol, São Paulo. Disponível em: <https://portugues.uol.com.br/gramatica/a-presidente-oupresidenta-qual-das-formas-devemos-utilizar.html>. Acesso em: 29 jun. 2018.

NUNES, José Horta. Uma articulação da análise de discurso com a história das ideias linguísticas. Letras. Santa Maria, v. 18, n. 2, p. 107-124, jul./dez., 2008.

ORLANDI, Eni P. Análise de Discurso: princípios e procedimentos. 11. ed. Campinas: Pontes Editores, 2013.

ORLANDI, Eni P. As formas do silêncio: no movimento dos sentidos. 6. ed. Campinas: Editora da Unicamp, 2007a.

ORLANDI, Eni P. Discurso e Texto: formulação e circulação de sentidos. 4. ed. Campinas: Pontes Editores, 2012.

ORLANDI, Eni. Política Linguística no Brasil. Campinas: Pontes, 2007b. p. 163-181.

PATI, Camila. O termo "presidenta" está mesmo errado gramaticalmente? Exame, Franca, 11 ago. 2016. Disponível em: <https://exame.abril.com.br/carreira/o-termo-presidenta-esta-mesmo-errado/>. Acesso em: 29 jun. 2018.

PÊCHEUX, Michel. Delimitações, inversões, deslocamentos. Traduzido por José Horta Nunes. Cadernos de Estudos Linguísticos, n. 19, p. 7-24, jul./dez., 1990.

PRATES, Maria Clara. Governo Temer veta palavra 'presidenta' em publicações da EBC. Estado de Minas, Belo Horizonte, 31 maio 2016. Disponível em: <https:/www.em.com.br/app/noticia/ politica/2016/05/31/interna_politica,767923/palavra-presidenta-e-vetada-na-ebc.shtml $>$. Acesso em: 29 jun. 2018.

iG. "Presidenta" existe na língua portuguesa desde 1872. Último Segundo iG, São Paulo, 15 set. 2011. Disponível em: <http://ultimosegundo.ig.com.br/educacao/presidenta-existe-na-lingua-portuguesadesde-1872/n1597210547562.html>. Acesso em: 29 jun. 2018.

RODRIGUES, Sérgio. Palavra do Ano: Presidente/presidenta. Veja, São Paulo, 21 out. 2010. Disponível em: <https://veja.abril.com.br/blog/sobre-palavras/palavra-do-ano-presidente-presidenta/>. Acesso em: 29 jun. 2018.

RODRIGUEZ, Diogo Antonio. Falar "presidenta" é tão correto quanto "presidente". CartaCapital, São Paulo, 29 nov. 2014. Disponível em: <https://www.cartacapital.com.br/politica/falar-201capresidenta201d-e-tao-correto-quanto-201 ca-presidente201d-3220.html>. Acesso em: 29 jun. 2018. 
